\title{
Micronutrients and cancer
}

\author{
I. T. Johnson \\ Institute of Food Research, Norwich Research Park, Colney, Norwich NR4 7UA, UK
}

\begin{abstract}
Adverse dietary factors account for approximately $30 \%$ of all cancers. Overconsumption of energy is undoubtedly one of the major risk factors, but dietary composition is also very important. In particular, a low consumption of fruits and vegetables appears to double the risk of carcinomas of the lung and alimentary tract. Epidemiological studies suggest that high plasma levels of Se, carotenoids and ascorbic acid are protective against cancer. However, intervention studies with antioxidant nutrients have given mixed results, and it has not been established that the benefits of a high intake of fruits and vegetables are invariably related to the prevention of oxidative DNA damage. Folic acid supplementation appears to protect against colo-rectal neoplasia, probably by preventing mutations associated with the repair of uracil mis-incorporation. However, there are indications from animal studies that exposure to high levels of folic acid at certain stages of development may lead to epigenetic effects that are, as yet, poorly understood. There seems little doubt that micronutrients contribute to the protective effects of plant foods against cancers of the lung and alimentary tract, but it has not been established that these benefits can be achieved using supplements.
\end{abstract}

Diet: Antioxidants: Selenium: Folate: Cancer

There is abundant epidemiological evidence to show that diet plays a major role in the aetiology of human cancers. In their much quoted review of the causes of cancer Doll $\&$ Peto (1981) concluded that between 10 and $70 \%$ of all cancers in the USA and other industrialised countries are caused by diet. This issue has been re-examined by a number of different authors and committees over the last two decades, but the general consensus that diet accounts for approximately $30 \%$ of all cancers remains intact (World Cancer Research Fund, 1997). This percentage represents a huge burden of disease that is, in principle at least, susceptible to prevention, but it is proving extremely difficult to translate epidemiological evidence into practical health policies. However, two main nutritional issues that bear directly on the risk of cancer at the population level have emerged. First, overweight, combined with low physical activity, is now recognised as a major cause of cancer in Western populations (Caan et al. 1998), and measures to discourage obesity at all stages of life have become a cornerstone of public health policy. Second, a relatively low intake of fruit and vegetables is an established risk factor for many of the most important cancers, in particular carcinomas of the alimentary tract and lungs (Block et al. 1992). The most recent large-scale evaluation of this issue, published as a Handbook of Cancer Prevention by the
International Agency for Research on Cancer (2003), has concluded that a higher intake of fruit probably lowers the risk of cancers of the oesophagus, stomach and lung, and a high intake of vegetables probably lowers the risk of cancers of the oesophagus and colon-rectum.

Plant foods are important sources of micronutrients, and this fact has focused attention on the possible role of vitamins and minerals in cancer prevention. Ames and colleagues (Ames, 1999; Ames \& Wakimoto, 2002) in particular have argued that suboptimal intake of vitamins and minerals is widespread in the West, and that this factor leads directly to DNA damage at levels comparable with the effects of ionising radiation. Fruit and vegetable consumption is generally static or declining in the West, whereas micronutrient supplements are relatively inexpensive and popular with consumers. Clearly, there would be much to be gained if micronutrient supplements could be used to produce even relatively modest reductions in cancer incidence over the coming decades (Ames \& Wakimoto, 2002). However, the range of foods included under the general heading of fruits and vegetables is very broad, the compositional data is still rather poor and there are many well-known difficulties associated with the accurate measurement of food intake. Adding to this complexity is the fact that fruits and vegetables contain

Corresponding author: I. T. Johnson, fax +441603 255167, email ian.johnson@bbsrc.ac.uk 
a huge range of other biologically-active constituents, which have been shown to exert anti-carcinogenic effects in vitro and in animal models (Johnson et al. 1994). It is hazardous, therefore, to attempt to deduce the preventative role of any particular class of food components from epidemiological data alone. The purpose of the present article is to consider critically the hypothesis that the correction of suboptimal micronutrient status might play a major protective role against cancer in Western populations. Much of the evidence for the protective effects of both fruits and vegetables and micronutrients relates to lung cancer, the most common cause of cancer worldwide, and to various cancers of the alimentary tract, which account for approximately one-quarter of fatal human neoplasms. These cancers therefore form the main subject matter for the present review. First, however, the general mechanisms of carcinogenesis will be briefly considered, together with some of the mechanisms through which micronutrients may influence them.

\section{Mechanisms of tumorigenesis}

The classic model of carcinogenesis involves three clearlydefined stages: initiation; promotion; progression (Pitot \& Dragan, 1994). Initiation is the stage at which cells in the target tissue acquire somatic mutations that are inherited through subsequent cycles of mitosis, giving rise to progeny that possess abnormalities of gene expression affecting proliferation, differentiation and cell survival (Bodmer, 1994). Promotion is characterised by further deregulation of proliferation and differentiation. In experimental carcinogenesis this stage may be brought about by further exposure to carcinogens, causing additional genetic damage in target cells already carrying oncogenic mutations, or by non-mutagenic promoters that enhance the proliferation and survival of initiated cells (Bodmer \& Tomlinson, 1996). Malignancy occurs when individual cells gain the ability to invade surrounding tissues, or translocate to other organs via the blood or lymph systems.

Damage to the genome, whether caused by exogenous carcinogens, by reactive oxygen species or by failure of synthesis or repair, is fundamental to the origins of cancer. These damaging agents are counterbalanced to some extent by food-borne anti-carcinogens, including both nutrients and biologically-active phytochemicals. However, individual susceptibility also depends on a host of metabolic factors, as well as genetic polymorphisms that are only just beginning to be understood (Johnson et al. 1994). The likelihood that oxidative damage to DNA and other intracellular macromolecules is a driver for both the initiation and promotion of cancer leads naturally to the hypothesis that a high intake of antioxidant nutrients is associated with a reduced risk of disease, and that evidence of this association should be detectable in epidemiological studies (Ames \& Wakimoto, 2002).

\section{Antioxidant defences}

Oxidative damage to DNA is caused by free radicals such as the hydroxyl radical $(\cdot \mathrm{OH})$, released from $\mathrm{H}_{2} \mathrm{O}_{2}$ in the presence of $\mathrm{Fe}, \mathrm{NO}$, and peroxynitrite $\left(\mathrm{ONOO}^{-}\right)$. These highly-reactive species are generated by a variety of mechanisms, including radiolysis of water as a result of ionising radiation (Teebor et al. 1988), by inflammatory processes (Hussain et al. 2003) or as a side-product of ordinary oxidative metabolism. Guanine is the mostreadily oxidised of the nucleotide bases, and the product 8-oxo-7,8-dihydro-2'-deoxyguanosine is widely used as a biomarker of DNA damage (Poulsen et al. 1999). Cells have evolved an arsenal of antioxidant mechanisms to defend macromolecules from free-radical-mediated damage. Nevertheless, the steady-state level of oxidative DNA adduct formation in old but otherwise normal laboratory rats has been estimated to be about 66000 adducts per cell (Helbock et al. 1998), leading to persistent lesions, mutations resulting from faulty DNA repair and strand breaks (Bjelland \& Seeberg, 2003). Free-radical reactions can also cause oxidative damage to proteins, such as p53, that are involved in the regulation of cellular proliferation and apoptosis, and can thereby contribute directly to tumour promotion (Hofseth et al. 2003).

Fruits, vegetables and cereals are the main sources of the antioxidant nutrients ascorbic acid and $\alpha$-tocopherol and of the carotenoids, including $\beta$-carotene, which is also a source of vitamin A. Dietary intake of carotenoids and levels of carotenoids in the blood have both been shown to be inversely related to the risk of cancers of the oropharyngeal tissues and lung in a number of case-control studies (International Agency for Research on Cancer, 1998), and this finding has contributed substantially to the development of the antioxidant hypothesis. However, attempts to reproduce the protective effects of fruits and vegetables using carotenoid supplements have largely failed. A major review conducted by the International Agency for Research on Cancer (1998) has concluded that the evidence for a protective effect of $\beta$-carotene and other carotenoids against cancer is inadequate. The hypothesis that ascorbic acid from dietary sources protects against death from chronic diseases, including cancer, is strongly supported by the recent study of Khaw et al. (2001), based on the East Anglian cohort of the European Prospective Investigation into Cancer and Nutrition. In this prospective population study a reduced risk of mortality from cancer has been shown to be associated with ascorbate in both men and women, although the relationship is significant $(P=0 \cdot 011)$ for men, but not for women $(P=0 \cdot 81)$.

\section{Antioxidant nutrients and cancers of the gastrointestinal tract}

Case-control studies provide some evidence for a protective effect of antioxidant vitamins against colo-rectal neoplasias. In a series of case-control studies conducted in northern Italy, La Vecchia et al. (1988) have observed a protective effect of fruit and vegetable consumption against colo-rectal cancer, and estimated, on the basis of multivariate odds ratios adjusted for total energy intake, that the combined effect of a low intake of $\beta$-carotene and ascorbic acid accounts for $43 \%$ of all colo-rectal cancer cases in their target population. West et al. (1989) have also observed a protective effect of $\beta$-carotene of approximately 
this magnitude in a case-control study conducted in Utah, USA. More recently, a small case-control study described by Breuer-Katschinski et al. (2001a) has also shown a protective effect of $\beta$-carotene intake, but not other antioxidant vitamins, against colo-rectal polyps. Moreover, an analysis of serum levels of antioxidants has shown an inverse relationship between vitamin A levels and risk of adenomas (Breuer-Katschinski et al. 2001b). In a recently published study Satia-Abouta et al. (2003) have explored the influence of micronutrient intakes on risk of colo-rectal cancer in a relatively large group of both white and black Americans. In both groups high intakes of vitamin $\mathrm{C}$ and $\beta$-carotene were found to be protective, with vitamin $\mathrm{E}$ being protective only in the African Americans.

The generally slow development of colo-rectal cancer via the adenoma-carcinoma sequence, and the fact that patients who have undergone polypectomy are routinely screened for recurrence, provides a convenient means of assessing the efficacy of dietary or pharmacological interventions designed to inhibit the development of adenomas. McKeown-Eyssen et al. (1988) have used this method to assess the effect of supplementation with ascorbic acid (400 mg/d) and $\alpha$-tocopherol $(400 \mathrm{mg} / \mathrm{d})$ in 200 patients previously shown to be free of polyps following endoscopic polypectomy. After 2 years of supplementation 137 subjects had completed the study. Recurrence of polyps was observed in $41.4 \%$ of seventy subjects on vitamin supplements and in $50.7 \%$ of sixty-seven subjects on placebos. After adjustment for various demographic and dietary factors, the relative risk of polyp occurrence was reported to be $0.86(95 \% \mathrm{CI} 0.51,1.43)$. The authors concluded that any effect of the intervention with antioxidants was too small to have been measured under the conditions of their trial.

Greenberg et al. (1994) randomly assigned 864 patients to four treatment groups to receive respectively: a placebo; $\beta$ carotene ( $25 \mathrm{mg}$ daily); vitamin C (1 g daily) and vitamin $\mathrm{E}$ ( $400 \mathrm{mg}$ daily); a combined dose of both $\beta$-carotene and vitamins $\mathrm{C}$ and $\mathrm{E}$. Complete colonoscopic examinations were performed 1 and 4 years after the patients entered the study. A total of 751 patients completed the study but there was no evidence that $\beta$-carotene or vitamins $\mathrm{C}$ and $\mathrm{E}$ reduce the incidence of adenomas. More recently, Hofstad et al. (1998) have carried out an intervention study in 116 polyp-bearing patients who received placebo or a mixture of $\beta$-carotene $(15 \mathrm{mg})$, vitamin C (150 mg), vitamin E (75 mg), Se $(101 \mu \mathrm{g})$ and $\mathrm{CaCO}_{3}(1.6 \mathrm{~g})$ daily for a period of 3 years, with annual colonoscopy. All polyps of $<10 \mathrm{~mm}$ at enrolment or follow-up were left unresected until the end of the study, so that both recurrence and growth could be quantified. No differences in the growth of adenomas were observed between the intervention group and the placebo group either from year to year or for the total study period, but there was a reduced recurrence of polyps in the intervention group compared with the controls. However, this effect could well have been associated with the $\mathrm{Ca}$, which has been shown convincingly to inhibit adenoma recurrence in other trials (Baron et al. 1999).

The failure of intervention with antioxidants during what is, inevitably, a narrow window in disease development cannot entirely rule out the possibility that prolonged exposure to antioxidants before the appearance of precancerous lesions may be protective. However, according to Connelly et al. (2003) patients with adenoma who have high levels of ascorbic acid in their plasma are much less likely to have high levels of crypt cell apoptosis. This mechanism is important for the deletion of precancerous cells (Johnson, 2001); antioxidant supplements may therefore actually inhibit the ability of the colonic mucosa to resist the development of pre-neoplastic lesions in patients already at risk of adenomas.

Gastric cancer is strongly associated with inflammatory effects resulting from infection with the bacterium Helicobacter pylori, and a chronic inflammatory response to reflux oesophagitis is the major risk factor for oesophageal adenocarcinoma (Ambs et al. 1999). Casecontrol studies have suggested a protective effect of plant food intake against tumours of the upper gastrointestinal tract (Kono \& Hirohata, 1996; Mayne et al. 2001), but it is difficult to attribute the protective effects specifically to ascorbic acid or other antioxidants. One study (Serafini et al. 2002) has explored the importance of antioxidant effects directly, using food intake data derived from a food-frequency questionnaire to calculate the total antioxidant potential of the foods consumed. A strong significant protective effect of total antioxidant potential against gastric cancers of both the cardia and more distal sites was found (odds ratio 0.65 (95\% CI 0.48, 0.89) for the highest quartile of antioxidant activity). However, this approach makes it impossible to distinguish the antioxidant effects of nutrients from those of non-nutrient secondary plant metabolites such as flavonoids, which may themselves exert protection against cancer of the stomach and oesophagus via other, non-antioxidant, effects (Sun et al. 2002).

\section{Lung cancer}

The primary risk factor for lung cancer is chronic exposure to tobacco smoke (Hecht, 1999), but both genetic and environmental factors modulate the risk to any particular individual. The World Cancer Research Fund (1997) report concluded that there is 'convincing' evidence of a protective effect of fruits and vegetables, a 'probable' protective effect of carotenoids and 'possible' protection from vitamin $\mathrm{C}$, vitamin $\mathrm{E}$ and Se. There is considerable interest in the possibility of using diet or chemo-prevention to reduce the risk of lung cancer in smokers (van Zandwijk \& Hirsch, 2003).

The Alpha-Tocopherol, Beta Carotene Cancer Prevention Study was designed to test the hypothesis that prolonged exposure to supplements of $\alpha$-tocopherol $(50 \mathrm{mg} / \mathrm{d}), \beta$ carotene $(20 \mathrm{mg} / \mathrm{d})$ or a combination of the two would reduce the incidence of lung cancer in smokers (AlphaTocopherol, Beta Carotene Cancer Prevention Study Group, 1994). In this study $>29000$ male Finnish smokers were randomly assigned to four groups receiving one of the three supplements or a placebo, and were followed up for 5-8 years. In the cohort 876 new cases of lung cancer were reported; with no protective effect of any treatment and a significant increase in the incidence of lung cancer amongst the participants receiving $\beta$-carotene $(P=0 \cdot 01)$. 
Somewhat similar findings were reported later from the Beta Carotene and Retinol Efficacy Trial (Omenn et al. 1996). It is now generally accepted that whereas $\alpha$ tocopherol exerts no protective effect against lung cancer in smokers, $\beta$-carotene appears to promote the disease process to a marked extent.

\section{Mechanistic studies}

The mutation frequency of the hypoxanthine-guanine phosphoribosyltransferase gene in $\mathrm{T}$ lymphocytes is used as a biomarker of somatic mutation in human subjects exposed to genotoxins. Nyberg et al. (2003) have used this biomarker to search for evidence of protective effects of fruits and vegetables against somatic mutations in 312 volunteers, of whom 158 were patients with lung cancer and 154 were healthy controls. Dietary intakes of various categories of vegetables and fruits, carotenoids, vitamin $\mathrm{A}$ and ascorbic acid were calculated using food composition tables and a food-frequency questionnaire. Protective effects against risk of mutation were observed in subjects with relatively high intakes of vegetables, citrus fruits, berries and ascorbic acid. However, the effect of $\beta$-carotene was found to be more complex, in that a ' $U$ '-shaped relationship between exposure and mutation frequency was observed, implying that both high and low intakes may increase the risk of mutation. This finding is consistent with the adverse effects of $\beta$-carotene supplementation on the risk of lung cancer reported in the AlphaTocopherol, Beta Carotene Cancer Prevention Study (Alpha-Tocopherol, Beta Carotene Cancer Prevention Study Group, 1994) and the Beta Carotene and Retinol Efficacy Trial (Omenn et al. 1996).

Many trials have been undertaken over the last few years to test the antioxidant hypothesis directly by measuring the effects of vitamin supplements against biomarkers of oxidative damage. Urinary excretion of 8-oxo-7,8dihydro-2'-deoxyguanosine is often used to provide a quantitative estimate of the formation of DNA adducts (Loft \& Poulsen, 1999) and the comet assay can provide direct evidence of DNA strand-breaks (Collins, 2002). However, in a review of intervention studies designed to quantify the effects of antioxidant supplements on oxidative damage to human leucocytes Møller \& Loft (2002) described a variety of technical limitations and inconclusive results, and concluded that the case for the long-term efficacy of antioxidants as a means of preventing DNA damage remains unproven (Møller \& Loft, 2002).

Møller et al. (2003) have recently attempted to test the putative role of antioxidant micronutrients directly by means of a placebo-controlled intervention study with fortythree human volunteers. The subjects were randomised into three groups and received an antioxidant-free basal diet plus $600 \mathrm{~g}$ fruits and vegetables, a supplement containing the corresponding amounts of vitamins and minerals or the placebo for $24 \mathrm{~d}$. Blood and urine samples were collected before, during and after the intervention, and the comet assay, excretion of 8-oxo-7,8-dihydro-2'-deoxyguanosine and markers of DNA repair activity were used to assess oxidative damage in leucocytes. At the end of the intervention period no clear evidence was found that either the fruits and vegetables or the vitamins and minerals had markedly reduced the level of oxidative DNA damage in mononuclear-cell DNA or levels of markers in the urine. Similarly, Jacob et al. (2003) assessed lipid and protein oxidation in thirty-nine healthy male non-smokers and thirty-eight smokers whose typical diet provided only 2.6 servings of fruits and vegetables daily. The volunteers received a daily supplement $(272 \mathrm{mg}$ vitamin $\mathrm{C}, 31 \mathrm{mg}$ $\alpha$-tocopherol and $400 \mu \mathrm{g}$ folic acid) or a placebo for $90 \mathrm{~d}$ with their usual diet. Lipid peroxidation products, including $\mathrm{F}(2)$-total and 8-isoprostanes, and protein carbonyls were determined in urine before and after supplementation. Supplementation increased plasma ascorbate and tocopherol levels, but had no effect on the levels of oxidant biomarkers. These findings may reflect a lack of sensitivity in the biomarkers currently available, but the hypothesis that supplementation with antioxidant nutrients provides protection against potentially-carcinogenic oxidative damage to DNA in healthy human subjects remains essentially unproven.

\section{Selenium}

The element Se is required for the synthesis of approximately twelve mammalian selenoproteins, in which it occurs as selenocysteine. Se deficiency in animals is associated with signs of oxidative damage, and in man a specific cardiomyopathy (Keshan disease) has been shown to be associated with a low intake of dietary Se $(<12 \mu \mathrm{g} / \mathrm{d}$; Tan et al. 2002). Epidemiological evidence for protective effects of Se against a range of human cancers has attracted interest and speculation for over three decades. Of approximately 100 animal studies of Se using model carcinogens, approximately $60 \%$ have provided evidence for anti-carcinogenic effects (Whanger, 2004). The selenoprotein glutathione peroxidase is a cytosolic antioxidant enzyme that catalyses the reduction of organic peroxides by reduced glutathione. This process is an essential component of the mammalian antioxidant defence system, and glutathione peroxidase is expressed in tissues throughout the body. Rosa et al. (1998) have studied the effects of the synthetic anti-carcinogenic organoselenium compound 1,4-phenylenebis(methylene)selenocyanate (el-Bayoumy et al. 1995) on the formation of DNA adducts in rodent lung tissue after administration of the tobacco-smoke carcinogen 4-(methylnitrosamino)-1-(3-pyridyl)-1-butanone. This compound forms mutagenic covalent DNA adducts, but also causes oxidative damage to DNA, resulting in the formation of 8-hydroxy-2'-deoxyguanosine, which can be measured directly in lung tissue. Dietary supplementation with 1,4-phenylenebis(methylene) selenocyanate $(15 \mathrm{mg} / \mathrm{kg}$ ) before and after treatment with 4-(methylnitrosamino)-1(3-pyridyl)-1-butanone prevents the increased levels of 8-hydroxy-2'-deoxyguanosine that occur in control rats.

Se metabolites exert a variety of biological effects other than the modulation of antioxidant defences. Organic Se compounds inhibit the formation of covalent DNA adducts. For example, 1,4-phenylenebis(methylene)selenocyanate inhibits the formation of DNA adducts in mammary tissue of rodents treated with the carcinogen 7,12-dimethylbenz(a)anthracene (el-Bayoumy et al. 1992). 
Inorganic Se compounds can themselves cause DNA strand breaks at high concentrations, but low-molecularweight organic Se compounds have been shown to induce apoptosis in tumour cells in vitro (Lu et al. 1995). Thus, Se joins a growing list of food components that enhance apoptosis of cells carrying genomic damage, and may thereby enhance deletion of cells that would otherwise go on to develop into malignant tumours (Johnson, 2001). Se also suppresses tumour cell proliferation via mechanisms related to inhibition of regulatory enzymes, including protein kinase C; also, Se may enhance DNA repair and may suppress aberrant methylation of DNA by inhibiting the activity of DNA methyltransferases (Fiala et al. 1998).

Interest in the putative relationship between $\mathrm{Se}$ and cancer began with population studies showing inverse relationships between estimated dietary exposure to Se and mortality from cancers of the colon, rectum, prostate, breast, ovary and lung, and with leukaemia (Schrauzer et al. 1977). Willett et al. (1983) have measured Se levels in serum from subjects in whom cancer developed during the subsequent 5 years and compared these with matched controls who remained healthy. The mean Se level for the cancer cases was found to be about $5 \%$ lower than that for the controls, but the risk of cancer for subjects in the lowest quintile of serum Se was twice that for subjects in the highest quintile. The association between low serum Se level and cancer was found to be strongest for gastrointestinal and prostate cancers. Many, although not all, subsequent studies have provided additional support for the hypothesis that low Se status increases the risk of many cancers (Whanger, 2004).

\section{Selenium and cancers of the alimentary tract}

Patients with colo-rectal neoplasia have lower basal levels of both serum Se and plasma glutathione peroxidase than controls (Rumi et al. 1992; Russo et al. 1997), and both variables are normalised by intervention with Se (Al-Taie et al. 2003). Animal studies support the hypothesis that risk of colo-rectal cancer is linked with low Se status (Jacobs, 1983), and recent work (Finley et al. 2000) suggests that Se supplied in the form of selenised broccoli is a more effective inhibitor of 1,2-dimethylhydrazineinduced colo-rectal neoplasia than either Se or low-Se broccoli alone. This finding emphasises the need for further research on the most effective organic forms of $\mathrm{Se}$ for use in human nutrition and chemo-prevention.

Intervention studies with multivitamin and mineral supplements, including Se, have been carried out in Linxian, China, where there are low soil levels of Se coupled with some of the highest rates of squamous cell carcinoma of the oesophagus in the world (Wei et al. 2004). These trials have provided evidence of a reduction in mortality from oesophageal and gastric cancers in the Se-supplemented groups, although the effects are relatively modest ( $\mathrm{Li}$ et al. 1993). The strongest current evidence for a protective effect of Se against colo-rectal cancer is provided by the data from the Nutritional Prevention of Cancer Trial. This randomised double-blind placebo-controlled intervention study was carried out on patients with a history of nonmelanoma skin cancer living in regions of the USA where the Se levels in the soil are low (Clark et al. 1996). Patients were randomised to receive either $200 \mu \mathrm{g}$ Se in the form of a high-Se yeast supplement/d or a yeast placebo. The primary purpose of the study was to test the hypothesis that Se supplementation would reduce the reoccurrence of skin cancer, but overall mortality and incident cases of lung, prostate and colo-rectal cancers were included as secondary end points. After a total follow-up of 8271 person-years no significant differences were found in the incidence of basal cell or squamous cell skin cancer between groups. However, when compared with the controls the patients treated with Se were found to have a significantly lower risk of mortality from all cancers (relative risk $0.50(95 \%$ CI $0.31,0.80))$, lower total cancer incidence and lower incidences of lung, colo-rectal and prostate cancers. As a result of these findings the study was terminated early, and all patients were made aware of the results and offered Se supplements.

\section{Lung cancer}

Toenail Se has been used as a marker of long-term Se status in studies on $\mathrm{Se}$ as a putative protective factor against lung cancer. Van den Brandt et al. (1993) have investigated this relationship in a cohort of 120852 Dutch men and women aged 55-69 years. The rate ratio of lung cancer for subjects in the highest quintile of toenail Se compared with the lowest quintile was reported to be 0.50 $(95 \%$ CI $0 \cdot 30,0 \cdot 81)$, with an inverse trend across quintiles. As with an earlier study of Willet et al. (1983), evidence was found of an interaction between $\mathrm{Se}$ and other antioxidant vitamins, with the protective effect of Se being particularly high in subjects with a relatively low dietary intake of $\beta$-carotene or vitamin C. Subsequent studies have tended to provide mixed and inconclusive results. For example, a nested case-control study conducted on a large cohort of subjects in Finland, where dietary levels of Se are low, provided good evidence of enhanced risk of lung cancer amongst smokers with low plasma Se levels (Knekt et al. 1998). However, other prospective studies have provided only weak non-significant evidence of an inverse relationship between Se status and risk of lung cancer.

As with colo-rectal cancer, the strongest evidence for a preventive effect of Se against lung cancer comes from the results of the Nutritional Prevention of Cancer Trial. In a subsequent follow-up study (Reid et al. 2002), it was established that a further eight lung cancer cases had occurred in the Se-treated group and a further four cases in the controls. After taking this finding into account, the adjusted hazard ratio for lung cancer in the Se-treated group was found to be $0 \cdot 74$, and the difference between groups was no longer significant (hazard ratio 0.74 (95\% CI 0.44 , $1 \cdot 24), P=0 \cdot 26$ ). However, subgroup analysis shows that subjects receiving Se supplementation, who were in the lowest tertile of Se status when randomised to receive $\mathrm{Se}$ at the outset of the trial, were at significantly reduced risk compared with equivalent controls (hazard ratio $0.42(95 \%$ CI $0 \cdot 18,0.96), P=0 \cdot 04)$. Overall, the balance of evidence appears to be in favour of the hypothesis that low Se status increases the risk of lung cancer, and the risk may be increased if intake of antioxidant nutrients is low. 


\section{Prostate cancer}

The unexpected results of the Nutritional Prevention of Cancer Trial (Clark et al. 1996) have generated a great deal of interest in the possibility that Se supplements can be used in the chemo-prevention of prostate cancer, for which prospective studies continue to provide evidence for an inverse relationship with Se status. In the Netherlands Cohort Study (van den Brandt et al. 2003) there was evidence of an interaction between initial Se status and $\beta$-cryptoxanthin and vitamin $C$. Large-scale intervention trials are now in progress and a definitive conclusion as to the role of Se in the prevention of prostate cancer seems likely to be achieved within the next decade (Marshall, 2001).

\section{Folates}

Folate is essential for the synthesis, maintenance and repair of DNA. Conversion of dUMP to dTMP requires the reduction of 5,10-methylenetetrahydrofolate to 5-methyltetrahydrofolate by the enzyme methyltetrahydrofolate reductase. Any marked reduction in the availability of 5,10-methylenetetrahydrofolate leads to an imbalance in deoxynucleoside triphosphate pools, and the presence of excess dUMP can cause misincorporation of uracil into DNA, faulty DNA repair and excess double-strand breaks (Wickramasinghe \& Fida, 1994). Moreover, changes in the level of 5-methyltetrahydrofolate within the cell can compromise the availability of the universal methyl donor $S$-adenosylmethionine, and hence interfere with the normal methylation of cytosine residues in DNA. Cytosine occurs at its highest density in human genome within cytosine-guanine dinucleotide sequences termed $\mathrm{CpG}$ islands, located predominantly in promoters and first exons of genes. CpG islands are unmethylated in expressed genes; aberrant methylation can suppress gene expression and lead to inappropriate silencing of tumour suppressor (Issa, 2000a,b). An increased supply of folate does not necessarily lead to $\mathrm{CpG}$ island hypermethylation; indeed, a suboptimal level of folate can lead to a paradoxical hypermethylation of some target genes, at least in vitro (Jhaveri et al. 2001). Suboptimal folate levels have been proposed as a major cause of genetic damage leading to cancer (Ames, 2001), and convincing epidemiological evidence has emerged to suggest that chronic folate deficiency may contribute to both the initiation and promotion of epithelial neoplasias.

Many fully-methylated $\mathrm{CpG}$ islands in the human genome are associated with transposable elements. These 'parasitic elements' constitute $\leq 35 \%$ of the human DNA and must be kept transcriptionally silent to maintain genomic stability. However, some transposable elements are metastable, resulting in variable expressivity that can modify the transcription of other genes in their immediate vicinity (Rakyan et al. 2002). One example is the mouse agouti gene, which encodes a signal protein that modulates the production of melanin in hair follicles (Duhl et al. 1994). In the $A^{v y}$ (variable yellow) variant of this gene a transposable element has become inserted in the $5^{\prime}$ terminal region of the $A$ allele. The sequence contains a metastable CpG-rich promoter that, when unmethylated, causes aberrant expression of the agouti gene and results in a characteristic yellow coat colour. A wide variation in the extent of methylation occurs, resulting in a variety of intermediate-coloured phenotypes (Morgan et al. 1999). Varying the level of folate and methionine in the diets of a/a dams mated with $A^{v y} / a$ males modifies the coat colour of their offspring; this situation is a direct result of variation in the level of methylation of $\mathrm{CpG}$ islands in the $A^{v y}$ transposable element (Waterland \& Jirtle, 2003). These authors speculate that supplementation of human populations with folic acid, whether for the prevention of neuraltube defects or chemo-prevention of cancer, may have unexpected effects on epigenetic gene-regulatory mechanisms during human embryonic development.

\section{Colo-rectal cancer}

Folate intake has been shown to be inversely related to the risk of colo-rectal adenomas in both case-control and prospective studies. The relationship has been assessed in both the Health Professionals Follow-Up Study and the Nurses Health Study. The relative risk of adenoma was found to be 0.66 (95\% CI 0.46, 0.95 between high and low quintiles of intake) for women and 0.63 (95\% CI 0.41 , 0.98 ) for men, independently of dietary fibre or vitamins $\mathrm{C}$ and E (Giovannucci et al. 1993). The findings of other smaller studies have generally been consistent with these conclusions (Tseng et al. 1996). In some studies the risk of adenomas has been compared directly with folate status, and an inverse relationship between blood folate levels and adenoma risk has been observed (Bird et al. 1995; Paspatis et al. 1995a,b).

Similar levels of reduced risk with higher folate consumption have been observed in European populations. Benito et al. (1991) have conducted a case-control study in Majorca and they observed a protective effect of high folate consumption against colo-rectal cancer. Ferraroni et al. (1994) have observed similar effects of folate intake in northern Italy, but the protective effects associated with high intakes of ascorbic acid and $\beta$-carotene were larger.

Taken as a whole, the epidemiological evidence from approximately eleven case-control and cohort studies strongly suggests that within Westernised populations there is a reduction in the risk of colon cancer of approximately $40 \%$ in the highest consumers of folate compared with the lowest consumers (Giovannucci, 2002). However, the situation is complicated by the involvement of genetic factors that modify the effects of folate on the susceptibility to cancer in subgroups of the population. In about $35 \%$ of Caucasians there is a polymorphism at position 677 of the methylenetetrahydrofolate reductase gene that involves a cytosine to thymine transition (C677T), resulting in reduced enzyme activity. Homozygous individuals (TT) comprise about $11 \%$ of the population and have been reported to show abnormal folate metabolism, elevated levels of homocysteine (Frosst et al. 1995) and evidence of hypomethylation of genomic DNA in some tissues (Stern et al. 2000). Three studies have explored the risk of colo-rectal cancer in subgroups with the CC, CT and TT genotypes. Individuals with the $\mathrm{CC}$ and $\mathrm{CT}$ genotypes derive less protective effect from a 
high-folate diet than those with the TT genotype, but all three genotypes are at similar risk from diets low in folate and methionine or high in alcohol (Giovannucci, 2002).

\section{Lung cancer}

The possibility of a protective effect of folate against lung cancer has received relatively little attention. A casecontrol study conducted in Hawaii has shown an inverse relationship between lung cancer and intake of green vegetables and $\beta$-carotene, but has failed to find any protective effects of folate (Le Marchand et al. 1989). More recently, Jatoi et al. (2001) have been unable to find evidence of any relationship between risk of lung cancer and plasma or erythrocyte folate levels after making adjustments for possible confounding effects of treatment. However, Shen et al. (2003) have recently reported that in former smokers folate intake is higher amongst controls than amongst lung cancer cases and that folate intake above the control median value is associated with a $40 \%$ lower risk of lung cancer. Prospective studies on folate intake and the risk of lung cancer have also produced mixed results. Two large studies have provided evidence that folate, vitamin $\mathrm{C}$ and carotenoids are inversely related to the risk of lung cancer (Bandera et al. 1997; Voorrips et al. 2000). However, other studies have failed to observe any strong associations with diet and none with folate (Speizer et al. 1999; Hartman et al. 2001; Jatoi et al. 2001).

\section{Concluding remarks}

Epidemiological and experimental studies continue to support the hypothesis that diets rich in plant foods reduce the risk of cancers of the lung and alimentary tract, although the benefits to individuals probably depend on their genetic profile. The hypothesis that the protective effects of fruits and vegetables are primarily a result of the provision of antioxidants has not been confirmed. While there is every reason to pursue public health policies that encourage consumption of micronutrients at levels at least as high as the RDA, consumption of fruits and vegetables may be more effective. The overall benefits of plant foods probably reflect the combined effects of both micronutrients and secondary plant metabolites (phytochemicals). The possibility of synergistic interactions amongst these different classes of biologically-active plant constituent requires further investigation, as does the impact of agronomy and processing on the overall composition of plant foods.

\section{Acknowledgement}

I thank the Biotechnology and Biological Sciences Research Council for financial support.

\section{References}

Alpha-Tocopherol Beta Carotene Cancer Prevention Study Group (1994) The effect of vitamin $\mathrm{E}$ and beta carotene on the incidence of lung cancer and other cancers in male smokers. New England Journal of Medicine 330, 1029-1035.
Al-Taie OH, Seufert J, Karvar S, Adolph C, Mork H, Scheurlen M, Kohrle J \& Jakob F (2003) Selenium supplementation enhances low selenium levels and stimulates glutathione peroxidase activity in peripheral blood and distal colon mucosa in past and present carriers of colon adenomas. Nutrition and Cancer 46, 125-130.

Ambs S, Hussain SP, Marrogi AJ \& Harris CC (1999) Cancerprone oxyradical overload disease. IARC Scientific Publications 150, 295-302.

Ames BN (1999) Micronutrient deficiencies. A major cause of DNA damage. Annals of the New York Academy of Sciences 889, 87-106.

Ames BN (2001) DNA damage from micronutrient deficiencies is likely to be a major cause of cancer. Mutation Research $\mathbf{4 7 5}$, $7-20$.

Ames BN \& Wakimoto P (2002) Are vitamin and mineral deficiencies a major cancer risk? Nature Reviews Cancer 2, 694-704.

Bandera EV, Freudenheim JL, Marshall JR, Zielezny M, Priore RL, Brasure J, Baptiste M \& Graham S (1997) Diet and alcohol consumption and lung cancer risk in the New York State Cohort (United States). Cancer Causes and Control 8, 828-840.

Baron JA, Beach M, Mandel JS, van Stolk RU, Haile RW, Sandler RS et al. (1999) Calcium supplements for the prevention of colorectal adenomas. Calcium Polyp Prevention Study Group. New England Journal of Medicine 340, 101-107.

Benito E, Stiggelbout A, Bosch FX, Obrador A, Kaldor J, Mulet M \& Munoz N (1991) Nutritional factors in colorectal cancer risk: a case-control study in Majorca. International Journal of Cancer 49, 161-167.

Bird CL, Swendseid ME, Witte JS, Shikany JM, Hunt IF, Frankl HD, Lee ER, Longnecker MP \& Haile RW (1995) Red cell and plasma folate, folate consumption, and the risk of colorectal adenomatous polyps. Cancer Epidemiology Biomarkers and Prevention 4, 709-714.

Bjelland S \& Seeberg E (2003) Mutagenicity, toxicity and repair of DNA base damage induced by oxidation. Mutation Research 531, 37-80.

Block G, Patterson B \& Subar A (1992) Fruit, vegetables, and cancer prevention: a review of the epidemiological evidence. Nutrition and Cancer 18, 1-29.

Bodmer WF (1994) Cancer genetics. British Medical Bulletin 50, 517-526.

Bodmer WF \& Tomlinson I (1996) Population genetics of tumours. Ciba Foundation Symposium 197, 181-189.

Breuer-Katschinski B, Nemes K, Marr A, Rump B, Leiendecker B, Breuer N \& Goebell H (2001a) Colorectal adenomas and diet: a case-control study. Colorectal Adenoma Study Group. Digestive Diseases and Sciences 46, 86-95.

Breuer-Katschinski B, Nemes K, Marr A, Rump B, Leiendecker B, Breuer N \& Goebell H (2001b) Relation of serum antioxidant vitamins to the risk of colorectal adenoma. Digestion 63, 43-48.

Caan BJ, Coates AO, Slattery ML, Potter JD, Quesenberry CP Jr \& Edwards SM (1998) Body size and the risk of colon cancer in a large case-control study. International Journal of Obesity and Related Metabolic Disorders 22, 178-184.

Clark LC, Combs GF Jr, Turnbull BW, Slate EH, Chalker DK, Chow J et al. (1996) Effects of selenium supplementation for cancer prevention in patients with carcinoma of the skin. A randomized controlled trial. Nutritional Prevention of Cancer Study Group. Journal of the American Medical Association 276, 1957-1963.

Collins AR (2002) The comet assay. Principles, applications, and limitations. Methods in Molecular Biology 203, 163-177.

Connelly AE, Satia-Abouta J, Martin CF, Keku TO, Woosley JT, Lund PK \& Sandler RS (2003) Vitamin C intake and apoptosis 
in normal rectal epithelium. Cancer Epidemiology Biomarkers and Prevention 12, 559-565.

Doll R \& Peto R (1981) The causes of cancer: quantitative estimates of avoidable risks of cancer in the United States today. Journal of the National Cancer Institute 66, 1191-1308.

Duhl DM, Vrieling H, Miller KA, Wolff GL \& Barsh GS (1994) Neomorphic agouti mutations in obese yellow mice. Nature Genetics 8, 59-65.

el-Bayoumy K, Chae YH, Upadhyaya P, Meschter C, Cohen LA \& Reddy BS (1992) Inhibition of 7,12-dimethylbenz(a)anthracene-induced tumors and DNA adduct formation in the mammary glands of female Sprague-Dawley rats by the synthetic organoselenium compound, 1,4-phenylenebis(methylene)selenocyanate. Cancer Research 52, 2402-2407.

el-Bayoumy K, Upadhyaya P, Chae YH, Sohn OS, Rao CV, Fiala E \& Reddy BS (1995) Chemoprevention of cancer by organoselenium compounds. Journal of Cellular Biochemistry 22, Suppl., 92-100.

Ferraroni M, La Vecchia C, D'Avanzo B, Negri E, Franceschi S \& Decarli A (1994) Selected micronutrient intake and the risk of colorectal cancer. British Journal of Cancer 70, 1150-1155.

Fiala ES, Staretz ME, Pandya GA, El-Bayoumy K \& Hamilton SR (1998) Inhibition of DNA cytosine methyltransferase by chemopreventive selenium compounds, determined by an improved assay for DNA cytosine methyltransferase and DNA cytosine methylation. Carcinogenesis 19, 597-604.

Finley JW, Davis CD \& Feng Y (2000) Selenium from high selenium broccoli protects rats from colon cancer. Journal of Nutrition 130, 2384-2389.

Frosst P, Blom HJ, Milos R, Goyette P, Sheppard CA, Matthews RG, Boers GJ, den Heijer M, Kluijtmans LA, van den Heuvel LP \& Rozen RA (1995) A candidate genetic risk factor for vascular disease: a common mutation in methylenetetrahydrofolate reductase. Nature Genetics 10, 111-113.

Giovannucci E (2002) Epidemiologic studies of folate and colorectal neoplasia: a review. Journal of Nutrition 132, 2350S-2355S.

Giovannucci E, Stampfer MJ, Colditz GA, Rimm EB, Trichopoulos D, Rosner BA, Speizer FE \& Willett WC (1993) Folate, methionine, and alcohol intake and risk of colorectal adenoma. Journal of the National Cancer Institute 85, 875-884.

Greenberg ER, Baron JA, Tosteson TD, Freeman DH Jr, Beck GJ, Bond JH et al. (1994) A clinical trial of antioxidant vitamins to prevent colorectal adenoma. Polyp Prevention Study Group. New England Journal of Medicine 331, 141-147.

Hartman TJ, Woodson K, Stolzenberg-Solomon R, Virtamo J, Selhub J, Barrett MJ \& Albanes D (2001) Association of the Bvitamins pyridoxal 5'-phosphate $(\mathrm{B}(6)), \mathrm{B}(12)$, and folate with lung cancer risk in older men. American Journal of Epidemiology 153, 688-694.

Hecht SS (1999) Tobacco smoke carcinogens and lung cancer. Journal of the National Cancer Institute 91, 1194-1210.

Helbock HJ, Beckman KB, Shigenaga MK, Walter PB, Woodall AA, Yeo HC \& Ames BN (1998) DNA oxidation matters: the HPLC-electrochemical detection assay of 8-oxo-deoxyguanosine and 8-oxo-guanine. Proceedings of the National Academy of Sciences USA 95, 288-293.

Hofseth LJ, Saito S, Hussain SP, Espey MG, Miranda KM, Araki Y et al. (2003) Nitric oxide-induced cellular stress and p53 activation in chronic inflammation. Proceedings of the National Academy of Sciences USA 100, 143-148.

Hofstad B, Almendingen K, Vatn M, Andersen SN, Owen RW, Larsen S \& Osnes M (1998) Growth and recurrence of colorectal polyps: a double-blind 3-year intervention with calcium and antioxidants. Digestion 59, 148-156.

Hussain SP, Hofseth LJ \& Harris CC (2003) Radical causes of cancer. Nature Reviews Cancer 3, 276-285.
International Agency for Research on Cancer (1998) Carotenoids. IARC Handbooks of Cancer Prevention, vol. 2. Lyon, France: IARC Press.

International Agency for Research in Cancer (2003) Fruit and Vegetables. IARC Handbooks of Cancer Prevention, vol. 8. Lyon, France: IARC Press.

Issa JP (2000a) The epigenetics of colorectal cancer. Annals of the New York Academy of Sciences 910, 140-153.

Issa JP (2000b) The epigenetics of colorectal cancer. Discussion. Annals of the New York Academy of Sciences 910, 153-155.

Jacob RA, Aiello GM, Stephensen CB, Blumberg JB, Milbury PE, Wallock LM \& Ames BN (2003) Moderate antioxidant supplementation has no effect on biomarkers of oxidant damage in healthy men with low fruit and vegetable intakes. Journal of Nutrition 133, 740-743.

Jacobs MM (1983) Selenium inhibition of 1,2-dimethylhydrazineinduced colon carcinogenesis. Cancer Research 43, 1646-1649.

Jatoi A, Daly BD, Kramer G \& Mason JB (2001) Folate status among patients with non-small cell lung cancer: a case-control study. Journal of Surgical Oncology 77, 247-252.

Jhaveri MS, Wagner C \& Trepel JB (2001) Impact of extracellular folate levels on global gene expression. Molecular Pharmacology 60, 1288-1295.

Johnson I, Williamson G \& Musk S (1994) Anticarcinogenic factors in plant foods: a new class of nutrients? Nutrition Research Reviews 7, 175-204.

Johnson IT (2001) Mechanisms and anticarcinogenic effects of diet-related apoptosis in the intestinal mucosa. Nutrition Research Reviews 14, 229-256.

Khaw KT, Bingham S, Welch A, Luben R, Wareham N, Oakes S \& Day N (2001) Relation between plasma ascorbic acid and mortality in men and women in EPIC-Norfolk prospective study: a prospective population study. European Prospective Investigation into Cancer and Nutrition. Lancet 357, 657-663.

Knekt P, Marniemi J, Teppo L, Heliovaara M \& Aromaa A (1998) Is low selenium status a risk factor for lung cancer? American Journal of Epidemiology 148, 975-982.

Kono S \& Hirohata T (1996) Nutrition and stomach cancer. Cancer Causes and Control 7, 41-55.

La Vecchia C, Negri E, Decarli A, D’Avanzo B, Gallotti L, Gentile A \& Franceschi S (1988) A case-control study of diet and colo-rectal cancer in northern Italy. International Journal of Cancer 41, 492-498.

Le Marchand L, Yoshizawa CN, Kolonel LN, Hankin JH \& Goodman MT (1989) Vegetable consumption and lung cancer risk: a population-based case-control study in Hawaii. Journal of the National Cancer Institute 81, 1158-1164.

Li B, Taylor PR, Li JY, Dawsey SM, Wang W, Tangrea JA et al. (1993) Linxian nutrition intervention trials. Design, methods, participant characteristics, and compliance. Annals of Epidemio$\operatorname{logy} 3,577-585$.

Loft S \& Poulsen HE (1999) Markers of oxidative damage to DNA: antioxidants and molecular damage. Methods in Enzymology 300, 166-184.

Lu J, Jiang C, Kaeck M, Ganther H, Vadhanavikit S, Ip C \& Thompson H (1995) Dissociation of the genotoxic and growth inhibitory effects of selenium. Biochemical Pharmacology 50, 213-219.

McKeown-Eyssen G, Holloway C, Jazmaji V, Bright-See E, Dion P \& Bruce WR (1988) A randomized trial of vitamins C and E in the prevention of recurrence of colorectal polyps. Cancer Research 48, 4701-4705.

Marshall JR (2001) Larry Clark's legacy: randomized controlled, selenium-based prostate cancer chemoprevention trials. Nutrition and Cancer 40, 74-77.

Mayne ST, Risch HA, Dubrow R, Chow WH, Gammon MD, Vaughan TL et al. (2001) Nutrient intake and risk of subtypes 
of esophageal and gastric cancer. Cancer Epidemiology Biomarkers and Prevention 10, 1055-1062.

Møller P \& Loft S (2002) Oxidative DNA damage in human white blood cells in dietary antioxidant intervention studies. American Journal of Clinical Nutrition 76, 303-310.

Møller P, Vogel U, Pedersen A, Dragsted LO, Sandstrom B \& Loft S (2003) No effect of 600 grams fruit and vegetables per day on oxidative DNA damage and repair in healthy nonsmokers. Cancer Epidemiology Biomarkers and Prevention 12, 1016-1022.

Morgan HD, Sutherland HG, Martin DI \& Whitelaw E (1999) Epigenetic inheritance at the agouti locus in the mouse. Nature Genetics 23, 314-318.

Nyberg F, Hou SM, Pershagen G \& Lambert B (2003) Dietary fruit and vegetables protect against somatic mutation in vivo, but low or high intake of carotenoids does not. Carcinogenesis 24, 689-696.

Omenn GS, Goodman GE, Thornquist MD, Balmes J, Cullen MR, Glass A et al. (1996) Effects of a combination of beta carotene and vitamin A on lung cancer and cardiovascular disease. New England Journal of Medicine 334, 1150-1155.

Paspatis GA, Kalafatis E, Oros L, Xourgias V, Koutsioumpa P \& Karamanolis DG (1995a) Folate status and adenomatous colonic polyps. A colonoscopically controlled study. Diseases of the Colon and Rectum 38, 64-67.

Paspatis GA, Kalafatis E, Oros L, Xourgias V, Koutsioumpa P \& Karamanolis DG (1995b) Folate status and adenomatous colonic polyps. A colonoscopically controlled study. Discussion. Diseases of the Colon and Rectum 38, 67-68.

Pitot HC \& Dragan YP (1994) The multistage nature of chemically induced hepatocarcinogenesis in the rat. Drug Metabolism Reviews 26, 209-220.

Poulsen HE, Weimann A \& Loft S (1999) Methods to detect DNA damage by free radicals: relation to exercise. Proceedings of the Nutrition Society 58, 1007-1014.

Rakyan VK, Blewitt ME, Druker R, Preis JI \& Whitelaw E (2002) Metastable epialleles in mammals. Trends in Genetics 18, 348-351.

Reid ME, Duffield-Lillico AJ, Garland L, Turnbull BW, Clark LC \& Marshall JR (2002) Selenium supplementation and lung cancer incidence: an update of the nutritional prevention of cancer trial. Cancer Epidemiology Biomarkers and Prevention 11, 1285-1291.

Rosa JG, Prokopczyk B, Desai DH, Amin SG \& El-Bayoumy K (1998) Elevated 8-hydroxy-2'-deoxyguanosine levels in lung DNA of A/J mice and F344 rats treated with 4-(methylnitrosamino)-1-(3-pyridyl)-1-butanone and inhibition by dietary 1,4-phenylenebis(methylene)selenocyanate. Carcinogenesis 19, $1783-1788$

Rumi G, Imre I, Sulle C, Sarudi I, Kelemen J \& Lassu Z (1992) Selenium in the blood of patients with colorectal cancer and neoplastic polyp. Acta Physiologica Hungarica 80, 275-279.

Russo MW, Murray SC, Wurzelmann JI, Woosley JT \& Sandler RS (1997) Plasma selenium levels and the risk of colorectal adenomas. Nutrition and Cancer 28, 125-129.

Satia-Abouta J, Galanko JA, Martin CF, Potter JD, Ammerman A \& Sandler RS (2003) Associations of micronutrients with colon cancer risk in African Americans and whites: results from the North Carolina Colon Cancer Study. Cancer Epidemiology Biomarkers and Prevention 12, 747-754.

Schrauzer GN, White DA \& Schneider CJ (1977) Cancer mortality correlation studies. III: Statistical associations with dietary selenium intakes. Bioinorganic Chemistry 7, 23-31.

Serafini M, Bellocco R, Wolk A \& Ekstrom AM (2002) Total antioxidant potential of fruit and vegetables and risk of gastric cancer. Gastroenterology 123, 985-991.
Shen H, Wei Q, Pillow PC, Amos CI, Hong WK \& Spitz MR (2003) Dietary folate intake and lung cancer risk in former smokers: a case-control analysis. Cancer Epidemiology Biomarkers and Prevention 12, 980-986.

Speizer FE, Colditz GA, Hunter DJ, Rosner B \& Hennekens C (1999) Prospective study of smoking, antioxidant intake, and lung cancer in middle-aged women (USA). Cancer Causes and Control 10, 475-482.

Stern LL, Mason JB, Selhub J \& Choi SW (2000) Genomic DNA hypomethylation, a characteristic of most cancers, is present in peripheral leukocytes of individuals who are homozygous for the C677T polymorphism in the methylenetetrahydrofolate reductase gene. Cancer Epidemiology Biomarkers and Prevention 9, 849-853.

Sun CL, Yuan JM, Lee MJ, Yang CS, Gao YT, Ross RK \& Yu MC (2002) Urinary tea polyphenols in relation to gastric and esophageal cancers: a prospective study of men in Shanghai, China. Carcinogenesis 23, 1497-1503.

Tan J, Zhu W, Wang W, Li R, Hou S, Wang D \& Yang L (2002) Selenium in soil and endemic diseases in China. The Science of the Total Environment 284, 227-235.

Teebor GW, Boorstein RJ \& Cadet J (1988) The repairability of oxidative free radical mediated damage to DNA: a review. International Journal of Radiation Biology 54, 131-150.

Tseng M, Murray SC, Kupper LL \& Sandler RS (1996) Micronutrients and the risk of colorectal adenomas. American Journal of Epidemiology 144, 1005-1014.

van den Brandt PA, Goldbohm RA, van't Veer P, Bode P, Dorant E, Hermus RJ \& Sturmans F (1993) A prospective cohort study on selenium status and the risk of lung cancer. Cancer Research 53, 4860-4865.

van den Brandt PA, Zeegers MP, Bode P \& Goldbohm RA (2003) Toenail selenium levels and the subsequent risk of prostate cancer: a prospective cohort study. Cancer Epidemiology Biomarkers and Prevention 12, 866-871.

van Zandwijk N \& Hirsch FR (2003) Chemoprevention of lung cancer: current status and future prospects. Lung Cancer $\mathbf{4 2}$, Suppl. 1, S71-S79.

Voorrips LE, Goldbohm RA, Brants HA, van Poppel GA, Sturmans F, Hermus RJ \& van den Brandt PA (2000) A prospective cohort study on antioxidant and folate intake and male lung cancer risk. Cancer Epidemiology Biomarkers and Prevention 9, 357-365

Waterland RA \& Jirtle RL (2003) Transposable elements: targets for early nutritional effects on epigenetic gene regulation. Molecular and Cellular Biology 23, 5293-5300.

Wei WQ, Abnet CC, Qiao YL, Dawsey SM, Dong ZW, Sun XD, Fan JH, Gunter EW, Taylor PR \& Mark SD (2004) Prospective study of serum selenium concentrations and esophageal and gastric cardia cancer, heart disease, stroke, and total death. American Journal of Clinical Nutrition $\mathbf{7 9}$, $80-85$.

West DW, Slattery ML, Robison LM, Schuman KL, Ford MH, Mahoney AW, Lyon JL \& Sorensen AW (1989) Dietary intake and colon cancer: sex- and anatomic site-specific associations. American Journal of Epidemiology 130, 883-894.

Whanger PD (2004) Selenium and its relationship to cancer: an update dagger. British Journal of Nutrition 91, 11-28.

Wickramasinghe SN \& Fida S (1994) Bone marrow cells from vitamin B12- and folate-deficient patients misincorporate uracil into DNA. Blood 83, 1656-1661.

Willett WC, Polk BF, Morris JS, Stampfer MJ, Pressel S, Rosner B, Taylor JO, Schneider K \& Hames CG (1983) Prediagnostic serum selenium and risk of cancer. Lancet ii, 130-134.

World Cancer Research Fund (1997) Food Nutrition and the Prevention of Cancer: A Global Perspective, pp. 216-251. Washington, DC: American Institute for Cancer Research. 
https://doi.org/10.1079/PNS2004389 Published online by Cambridge University Press 